Research Paper

\title{
Impacts of AURKA Genetic Polymorphism on Urothelial Cell Carcinoma Development
}

\author{
Chia-Hung Huang ${ }^{1,2^{*}}$, Chih-Jung Chen ${ }^{3,4^{*}}$, Pei-Ni Chen ${ }^{5}$, Shian-Shiang Wang ${ }^{4,6}$, Ying-Erh Chou ${ }^{1,4,7}$, \\ Sheng-Chun Hung ${ }^{1,4,6}$, Shun-Fa Yang $1,7 \bowtie$ \\ 1. Institute of Medicine, Chung Shan Medical University, Taichung, Taiwan \\ 2. Division of Nephrology, Department of Internal Medicine, Lin Shin Hospital, Taichung, Taiwan \\ 3. Department of Surgical Pathology, Changhua Christian Hospital, Changhua, Taiwan \\ 4. School of Medicine, Chung Shan Medical University, Taichung, Taiwan \\ 5. Institute of Biochemistry, Microbiology and Immunology, Chung Shan Medical University, Taichung, Taiwan \\ 6. Division of Urology, Department of Surgery, Taichung Veterans General Hospital, Taichung, Taiwan \\ 7. Department of Medical Research, Chung Shan Medical University Hospital, Taichung, Taiwan \\ *These authors contributed equally to the work. \\ $\square$ Corresponding author: Shun-Fa Yang, Ph.D. Institute of Medicine, Chung Shan Medical University, Taichung 402, Taiwan; Tel: +886-4-24739595 ext. 34253; \\ Fax: +886-4-24723229; E-mail: ysf@csmu.edu.tw \\ (c) Ivyspring International Publisher. This is an open access article distributed under the terms of the Creative Commons Attribution (CC BY-NC) license \\ (https://creativecommons.org/licenses/by-nc/4.0/). See http://ivyspring.com/terms for full terms and conditions.
}

Received: 2018.09.17; Accepted: 2019.01.16; Published: 2019.02.23

\begin{abstract}
Urothelial cell carcinoma (UCC) is the most common primary malignancy of the urinary system and the second-most common type of renal cell carcinoma. Aurora kinase A (AURKA), a serine/threonine kinase, has a critical role in centrosome duplication, spindle assembly checkpoint, and cytokinesis. Here, we determined the correlation between UCC susceptibility and AURKA polymorphisms. We used real-time polymerase chain reaction to compare the genotype distributions and allelic frequencies of four single-nucleotide polymorphisms (SNPs) of AURKA, namely rs 1047972, rs2273535, rs2064863, and rs6024836, between 431 UCC cases and 862 healthy controls. Logistic regression models demonstrated that the $G$ allele of rs2064863, a genetic polymorphism of AURKA, exhibited a significant protective effect against UCC among the 862 nonsmokers. Moreover, patients with rs $2064863 \mathrm{G}$ allele exhibited a slightly lower risk of lymph node metastasis and those with rs6024836 G allele exhibited a lower risk of distant metastases. Our study suggested that several variants of AURKA SNPs rs2064863 and rs6024836 may serve as critical predictors for the clinical status of UCC.
\end{abstract}

Key words: urothelial cell carcinoma, Aurora kinase A, susceptibility, single nucleotide polymorphism

\section{Introduction}

Urothelial cell carcinoma (UCC), also called transitional cell carcinoma, includes carcinomas affecting the bladder, urethra, ureters, and renal pelvis [1]. UCC is the most common type of bladder cancer, accounting for more than $90 \%$ of all bladder cancers, and it poses a challenge to radiologists [2]. Invasive urothelial carcinomas grow from the tissue lining of the bladder into the deeper layers of the bladder wall, and they can extend from the kidney collecting system to the bladder [2]. UCC of the bladder is the fifth-most common cancer in the United States [3]. For patients with metastatic UCC, cisplatin-based chemotherapy, the standard first-line treatment, provides a median overall survival of 13-16 months [4]. This finding emphasizes the need for expanding the armamentarium of reasonable treatment strategies for advanced UCC.

Aurora kinase A (AURKA) is a cell cycleregulated serine/threonine kinase involved in mitotic spindle formation, chromosome amplification and segregation, aneuploidy, G2/M phase transition during cell cycle, and malignant transformation [5]. AURKA may play a role in cancer development and progression as well as tumorigenesis, and it is 
frequently overexpressed or mutated in a wide range of human cancers, including lung, liver, prostate, cervix, ovary, and bladder cancers [5-8]. In patients with melanoma, AURKA overexpression is correlated with shortened survival and poor prognosis and driven by the activation of forkhead box M1 and mitogen activated protein kinase/extracellular-signalregulated kinase, as noted in BRAF-mutated melanoma cells [9]. AURKA overexpression is also associated with pathological stage and distant metastasis. Inhibition of this overexpression results in the regulation of epithelial-mesenchymal transition in hepatocellular carcinoma, which in turn limits cell invasion [8]. We previously demonstrated that betel nut chewing combined with C-A-T haplotypes of $A U R K A$ increased the risk of oral squamous cell carcinoma and that the AURKA single-nucleotide polymorphism (SNP) rs2064863 increased the risk of advanced-stage tumor development [10]. T/T homozygote carriers of AURKA rs1047972 are at a higher risk of hepatocellular carcinoma than $\mathrm{C} / \mathrm{C}$ homozygote wild-type carriers are [11]. AURKA rs2273535 is also associated with a high risk of breast cancer in Asians, whereas in Caucasians, AURKA rs1047972 is associated with a low risk of breast cancer risk [12]. Although AURKA SNPs increase the risk of cancer, including liver cancer, oral cancer, gastric cancer and breast cancer [10-13], their association with UCC remains unclear. In this case-control study, we assessed this relationship by investigating of four AURKA SNPs, namely rs1047972, rs2273535, rs2064863, and rs6024836, in Taiwanese patients with UCC.

\section{Materials and Methods}

\section{Study participants and ethics statement}

We analyzed 431 patients with UCC (272 men and 159 women; mean age $=68.6 \pm 11.8$ years) from the Taichung Veterans General Hospital, Taichung, Taiwan, between 2010 and 2015. We also included healthy controls that had no history of cancer at any site. All research participants were provided with a written description of the study including questions regarding their demographic characteristics. Their personal information was recorded based on their responses. This study was approved by the Institutional Review Board (IRB) of Taichung Veterans General Hospital (IRB no. CF11094), and written informed consent was obtained from all participants before the study was performed. Whole-blood samples collected from the patients and controls were placed in tubes containing ethylenediaminetetraacetic acid (EDTA), immediately centrifuged, and finally, frozen at $-80^{\circ} \mathrm{C}$ for future DNA extraction.

\section{AURKA SNP selection}

For this study, four AURKA SNPs, namely rs1047972, rs2273535, rs2064863, and rs6024836, with minor allele frequencies $>5 \%$ were selected from the International HapMap Project data. The selected SNPs were associated with tumor progression, including that in liver cancer, breast cancer and oral cancers [10, $12,14]$.

\section{DNA extraction and genotype determination}

Total genomic DNA was extracted from whole blood by using QIAamp DNA blood mini kits based on silica spin column capture (Qiagen, Valencia, CA, USA) for DNA isolation. DNA was eluted from the columns, dissolved in TE buffer, and quantified according to measurements of the optical density at $260 \mathrm{~nm}$. Each final prepared specimen was stored at $-20{ }^{\circ} \mathrm{C}$ and used as a template for quantitative polymerase chain reaction (PCR) analysis. Evaluation of AURKA polymorphisms were performed using TaqMan SNP genotyping assays with the ABI StepOne Real-time PCR System as previously described [10, 15]. The SNPs were further analyzed using SDS (version 3.0; Applied Biosystems, Foster City, CA, USA).

\section{Statistical analysis}

The Hardy-Weinberg equilibrium of the distribution of the genotypes of each SNP was estimated using the chi-square test. The distributions of demographic characteristics and genotype frequencies were compared between healthy controls and UCC cases by using Fisher's exact test and Mann-Whitney $U$ test. $p<0.05$ indicated statistically significant differences. Data were analyzed using SAS (version 9.1, 2005; SAS Institute Inc., Cary, NC).

\section{Results}

\section{Patient characteristics and distribution of UCC}

The demographic characteristics of the participants were statistically analyzed; the results are summarized in Table 1. In total, 431 patients with UCC and 862 healthy controls (mean age \pm standard deviation, $68.6 \pm 11.8$ and $57.2 \pm 10.0$ years, respectively) were included. The mean age of patients with UCC significantly differed from that of the control groups $(p<0.001)$. No significant differences were observed in the distributions of gender and cigarette smoking between patients and controls. Approximately $54.5 \%$ of the patients had been diagnosed with nonmuscle invasive tumor (stage pTa-pT1).

\section{Associations between AURKA SNPs and UCC}

The genotype distributions and allelic frequen- 
cies of AURKA polymorphisms of patients with UCC and control participants are denoted in Table 2. In our recruited control group, AURKA genotype distribution revealed that the most frequent alleles were homozygous C/C for rs1047972, homozygous T/T for rs2273535 and rs2064863, and heterozygous A/G for rs6024836. No significant differences were observed in the allele and genotype frequencies of rs1047972, rs2273535, rs2064863, or rs6024836 between the patients and controls (Table 2).

\section{Genotype distribution of AURKA SNPs among 862 nonsmokers}

We investigated genotype distributions of the four AURKA SNPs among 862 nonsmokers (300 patients with UCC and 562 controls; Table 3). After age and gender were controlled, among the 862 nonsmokers, individuals with the G/T genotype of rs2064863 demonstrated a significantly lower risk of UCC than those with the T/T genotype $(\mathrm{AOR}=0.669$, 95\% CI 0.454-0.986, $\mathrm{p}<0.05$; Table 3). Moreover, the individuals with the $\mathrm{G} / \mathrm{T}+\mathrm{G} / \mathrm{G}$ genotype of rs2064863 were at a significantly lower risk of UCC compared with those with the $\mathrm{T} / \mathrm{T}$ genotype $(\mathrm{AOR}=0.649,95 \%$ CI 0.447-0.944, p< 0.05; Table 3). We did not observe significant differences in the allele and genotype frequencies of rs1047972, rs2273535, or rs6024836 between the patients with UCC and controls.

Table 1. The distributions of demographical characteristics in 862 controls and 431 patients with UCC.

\begin{tabular}{|c|c|c|c|}
\hline Variable & $\begin{array}{l}\text { Controls } \\
(\mathrm{N}=862) \\
\mathrm{n}(\%)\end{array}$ & $\begin{array}{l}\text { Patients } \\
(\mathrm{N}=431) \\
\mathrm{n}(\%)\end{array}$ & p value \\
\hline Age (yrs) & & & $<0.001$ \\
\hline$\leqq 65$ & $697(80.9)$ & $166(38.5)$ & \\
\hline$>65$ & $165(19.1)$ & $265(61.5)$ & \\
\hline Mean \pm S.D. & $57.2 \pm 10$ & $68.6 \pm 11.8$ & $<0.001$ \\
\hline Gender & & & 0.365 \\
\hline Female & $296(34.3)$ & $159(36.9)$ & \\
\hline Male & $566(65.7)$ & $272(63.1)$ & \\
\hline Tobacco consumption & & & 0.113 \\
\hline No & $562(65.2)$ & $300(69.6)$ & \\
\hline Yes & $300(34.8)$ & $131(30.4)$ & \\
\hline \multicolumn{4}{|l|}{ Stage } \\
\hline Non muscle invasive tumor (pTa-pT1) & & $235(54.5)$ & \\
\hline Muscle invasive tumor (pT2-pT4) & & $196(45.5)$ & \\
\hline \multicolumn{4}{|l|}{ Tumor T status } \\
\hline Та & & $90(20.9)$ & \\
\hline T1-T4 & & $341(79.1)$ & \\
\hline \multicolumn{4}{|l|}{ Lymph node status } \\
\hline N0 & & $380(88.2)$ & \\
\hline $\mathrm{N} 1+\mathrm{N} 2$ & & $51(11.8)$ & \\
\hline \multicolumn{4}{|l|}{ Metastasis } \\
\hline M0 & & $417(96.8)$ & \\
\hline M1 & & $14(3.2)$ & \\
\hline \multicolumn{4}{|l|}{ Histopathologic grading } \\
\hline Low grade & & $53(12.3)$ & \\
\hline High grade & & $378(87.7)$ & \\
\hline
\end{tabular}

Table 2. Genotype Distributions of AURKA Gene Polymorphisms in 862 Controls and 431 Patients with UCC.

\begin{tabular}{|c|c|c|c|c|}
\hline Variable & $\begin{array}{l}\text { Controls } \\
(\mathrm{N}=862) \\
\mathrm{n}(\%)\end{array}$ & $\begin{array}{l}\text { Patients } \\
(\mathrm{N}=431) \\
\mathrm{n}(\%)\end{array}$ & OR $(95 \% \mathrm{CI})$ & AOR $(95 \%$ CI) \\
\hline \multicolumn{5}{|l|}{ rs1047972 } \\
\hline $\mathrm{CC}$ & $658(76.3 \%)$ & $319(74 \%)$ & 1.000 (reference) & 1.000 (reference) \\
\hline $\mathrm{TC}$ & $194(22.5 \%)$ & $106(24.6 \%)$ & 1.127 (0.859-1.479) & $1.136(0.831-1.553)$ \\
\hline TT & $10(1.2 \%)$ & $6(1.4 \%)$ & $1.238(0.446-3.435)$ & $1.599(0.495-5.167)$ \\
\hline $\mathrm{TC}+\mathrm{TT}$ & $204(23.7 \%)$ & $112(26 \%)$ & $1.132(0.868-1.478)$ & $1.156(0.851-1.570)$ \\
\hline \multicolumn{5}{|l|}{ rs2273535 } \\
\hline $\mathrm{TT}$ & $409(47.4 \%)$ & $190(44.1 \%)$ & 1.000 (reference) & 1.000 (reference) \\
\hline $\mathrm{AT}$ & $355(41.2 \%)$ & $192(44.5 \%)$ & $1.164(0.910-1.489)$ & $1.055(0.798-1.396)$ \\
\hline AA & $98(11.4 \%)$ & $49(11.4 \%)$ & $1.076(0.733-1.580)$ & $0.938(0.599-1.470)$ \\
\hline $\mathrm{AT}+\mathrm{AA}$ & $453(52.6 \%)$ & $241(55.9 \%)$ & $1.145(0.908-1.445)$ & $1.031(0.791-1.344)$ \\
\hline \multicolumn{5}{|l|}{ rs2064863 } \\
\hline $\mathrm{TT}$ & $591(68.6 \%)$ & $306(71 \%)$ & 1.000 (reference) & 1.000 (reference) \\
\hline GT & $243(28.2 \%)$ & $114(26.5 \%)$ & $0.906(0.697-1.177)$ & $0.791(0.586-1.067)$ \\
\hline GG & $28(3.2 \%)$ & $11(2.6 \%)$ & $0.759(0.373-1.545)$ & $0.505(0.220-1.160)$ \\
\hline $\mathrm{GT}+\mathrm{GG}$ & $271(31.4 \%)$ & $125(29 \%)$ & $0.891(0.692-1.147)$ & $0.758(0.568-1.013)$ \\
\hline \multicolumn{5}{|l|}{ rs6024836 } \\
\hline AA & $363(42.1 \%)$ & $173(40.1 \%)$ & 1.000 (reference) & 1.000 (reference) \\
\hline AG & $376(43.6 \%)$ & $201(46.6 \%)$ & $1.122(0.874-1.439)$ & $1.143(0.860-1.519)$ \\
\hline GG & $123(14.3 \%)$ & $57(13.2 \%)$ & $0.972(0.677-1.397)$ & $1.035(0.684-1.564)$ \\
\hline $\mathrm{AG}+\mathrm{GG}$ & $499(57.9 \%)$ & $258(59.9 \%)$ & $1.085(0.857-1.373)$ & $1.117(0.854-1.460)$ \\
\hline
\end{tabular}

Bold font indicates statistical significance $(\mathrm{p}<0.05)$. The odds ratio $(\mathrm{OR})$ with their $95 \%$ confidence intervals were estimated by logistic regression models. The adjusted odds ratio (AOR) with their $95 \%$ confidence intervals were estimated by multiple logistic regression models after controlling for age, gender and tobacco consumption.

Table 3. Genotype Distributions of AURKA Gene Polymorphisms among 862 non-smokers.

\begin{tabular}{lllll}
\hline Variable & $\begin{array}{l}\text { Controls } \\
\mathbf{( N = 5 6 2 )} \\
\mathbf{n}(\mathbf{9})\end{array}$ & $\begin{array}{l}\text { Patients } \\
\mathbf{( N = 3 0 0 )} \\
\mathbf{n}(\%)\end{array}$ & OR (95\% CI) & AOR (95\% CI) \\
\hline rs1047972 & & & & \\
CC & $434(77.2 \%)$ & $224(74.7 \%)$ & 1.000 (reference) & 1.000 (reference) \\
TC & $122(21.7 \%)$ & $72(24 \%)$ & $1.143(0.820-1.595)$ & $1.167(0.775-1.759)$ \\
TT & $6(1.1 \%)$ & $4(1.3 \%)$ & $1.292(0.361-4.624)$ & $2.266(0.493-10.414)$ \\
TC+TT & $128(22.8 \%)$ & $76(25.3 \%)$ & $1.150(0.830-1.594)$ & $1.209(0.810-1.805)$ \\
rs2273535 & & & & \\
TT & $263(46.8 \%)$ & $135(45 \%)$ & 1.000 (reference) & 1.000 (reference) \\
AT & $239(42.5 \%)$ & $132(44 \%)$ & $1.076(0.799-1.448)$ & $0.913(0.638-1.306)$ \\
AA & $60(10.7 \%)$ & $33(11 \%)$ & $1.071(0.668-1.719)$ & $0.808(0.448-1.456)$ \\
AT+AA & $299(53.2 \%)$ & $165(55 \%)$ & $1.075(0.811-1.424)$ & $0.892(0.635-1.253)$ \\
rs2064863 & & & & \\
TT & $382(68 \%)$ & $215(71.7 \%)$ & 1.000 (reference) & 1.000 (reference) \\
GT & $162(28.8 \%)$ & $76(25.3 \%)$ & $0.834(0.605-1.147)$ & $\mathbf{0 . 6 6 9 ( 0 . 4 5 4 - 0 . 9 8 6 )}$ \\
GG & $18(3.2 \%)$ & $9(3 \%)$ & $0.888(0.392-2.012)$ & $0.496(0.180-1.364)$ \\
GT+GG & $180(32 \%)$ & $85(28.3 \%)$ & $0.839(0.617-1.141)$ & $\mathbf{0 . 6 4 9}(\mathbf{0 . 4 4 7 - 0 . 9 4 4 )}$ \\
rs6024836 & & & & \\
AA & $231(41.1 \%)$ & $122(40.7 \%)$ & 1.000 (reference) & 1.000 (reference) \\
AG & $254(45.2 \%)$ & $145(48.3 \%)$ & $1.081(0.801-1.458)$ & $1.055(0.735-1.515)$ \\
GG & $77(13.7 \%)$ & $33(11 \%)$ & $0.811(0.511-1.289)$ & $0.715(0.407-1.255)$ \\
AG+GG & $331(58.9 \%)$ & $178(59.3 \%)$ & $1.018(0.766-1.354)$ & $0.975(0.691-1.375)$ \\
\hline Bold font indicates statistical significance (p < 0.05). The odds ratio (OR) with their \\
95\% confidence intervals were estimated by logistic regression models. The \\
adjusted odds ratio (AOR) with their 95\% confidence intervals were estimated by \\
multiple logistic regression models after controlling for age and gender.
\end{tabular}

\section{Associations between rs2064863 and clinical status of UCC}

The role of AURKA rs2064863 in the clinicopathological status of patients with UCC was assessed. To this end, we estimated the distribution frequency of clinical statuses, including tumor clinical stage, 
primary tumor size, lymph node involvement, distant metastases, and histopathological grading, as well as the frequency of AURKA genotypes in 431 patients with UCC. Among the 431 patients with UCC, patients with rs2064863 exhibited a 0.418 -fold lower risk of developing a lymph node metastasis status (N1 + N2) of UCC (95\% CI 0.191-0.917) than did patients with wild-type AURKA ( $\mathrm{p}=0.030)$. No significant difference was observed between these patient groups with regard to clinical stage, tumor size, distant metastases, or cell differentiation.

\section{Associations between rs6024836 and clinical status of UCC}

We further evaluated the associations of rs6024836 with various clinical characteristics of patients with UCC, including clinical tumor stage, tumor size, lymph node involvement, distant metastases, and histopathologic grading. The results indicated that the patients with rs6024836 exhibited a 0.257 -fold lower risk of distant metastases (M1) of UCC (95\% CI 0.079-0.832) than did patients with wild-type AURKA $(\mathrm{p}=0.023)$. No significant differences between these patient groups, with regard to clinical tumor stage, tumor size, lymph node involvement, or cell differentiation, were noted.

\section{Discussion}

Mitosis-regulating AURKA overexpression is strongly associated with cancer progression [16, 17], and genetic susceptibility is critical in various cancer types. Identifying the specific AURKA gene involved in susceptibility to cancer may aid the management of cancer risk. The genotypic polymorphisms of mitosisregulating AURKA have been described. Asian carriers of AURKA rs2273535 are at a high risk of breast cancer, but Caucasian carriers are not [18]. AURKA rs2273535 may increase susceptibility to UTUC [19]. Moreover, individuals who received alisertib for metastatic urothelial carcinoma, with the AA genotype of rs1047972 have longer progression-free survival compared with individuals with the wild-type TT genotype [20]. AURKA rs2273535 (T91A) is significantly associated with high oral cancer risk[21]. Although studies have demonstrated that AURKA SNPs are associated with a relatively high risk of tumors, few studies have addressed the relationship between AURKA genetic variants and UCC. In the present study, we did not observe an association between UCC risk and rs1047972, rs2273535, or rs6024836. Our data provided evidence that among nonsmokers, the carriers of at least one $G$ allele $(G / T$ or $G / G)$ in rs2064 863 were at a lower risk of UCC than were wild-type $\mathrm{T} / \mathrm{T}$ carriers (Table 3 ). These results suggested that genetic variation in AURKA may be associated with
UCC susceptibility and may interact with smoking. Furthermore, different AURKA SNPs have different roles in cancer susceptibility and progression.

Patients with UCC and increased AURKA mRNA expression in tumor tissues not only exhibit high rates of cancer metastasis and high-grade tumors but also have relatively low overall and UCC-specific survival [22]. AURKA overexpression also promotes cancer metastasis, increases drug resistance, and is associated with poor prognosis [23-26]. In a study on 786 men with oral cancer, patients with the GG genotype and $\mathrm{G}$ allele of AURKA rs2064863 were at a 1.365-fold higher risk of stage III or IV oral cancer than were those with the wild-type AA genotype [10]. Other reports on hepatocellular carcinoma have indicated that patients with at least one A allele (A/T or A/A genotype) in AURKA rs2273535 were less likely progress to stage III or IV (0.593-fold) and develop large tumors (0.591-fold)) [11]. Our study demonstrated that patients with UCC and with the $\mathrm{G} / \mathrm{G}$ genotype and $\mathrm{G}$ allele carriers of AURKA rs2064863 were at a low risk of lymph node metastases; however, this relationship did not extend to the clinical tumor stage, tumor size, metastasis to distant organs, or cell differentiation (Table 4). Similarly, the G/G genotype and G allele carriers of AURKA rs6024836 were associated with a low risk of distant metastases of UCC, but this relationship did not extend to the clinical tumor stage, tumor size, lymph node involvement, or cell differentiation (Table 5). These findings suggest that patients with at least one $\mathrm{G}$ allele in AURKA rs2064863 or rs6024836 are less likely to experience lymph node metastases or distant metastases, respectively.

Table 4. Distribution frequency of the clinical status and AURKA rs2064863 genotype frequencies in 431 UCC patients.

\begin{tabular}{|c|c|c|c|c|}
\hline \multirow[b]{2}{*}{ Variable } & \multicolumn{4}{|c|}{ AURKA (rs2064863) } \\
\hline & $\begin{array}{l}\text { TT (\%) } \\
(\mathrm{n}=306)\end{array}$ & $\begin{array}{l}\text { GT+GG (\%) } \\
(n=125)\end{array}$ & OR $(95 \% \mathrm{CI})$ & $\begin{array}{l}\mathrm{p} \\
\text { value }\end{array}$ \\
\hline \multicolumn{5}{|l|}{ Stage } \\
\hline $\begin{array}{l}\text { Non muscle invasive } \\
\text { tumor (pTa-pT1) }\end{array}$ & $163(53.3 \%)$ & $72(57.6 \%)$ & 1.000 (reference) & \\
\hline $\begin{array}{l}\text { Muscle invasive } \\
\text { tumor (pT2-pT4) }\end{array}$ & $143(46.7 \%)$ & $53(42.4 \%)$ & $0.839(0.551-1.277)$ & 0.413 \\
\hline \multicolumn{5}{|l|}{ Tumor T status } \\
\hline $\mathrm{Ta}$ & $62(20.3 \%)$ & $28(22.4 \%)$ & 1.000 (reference) & \\
\hline $\mathrm{T} 1-\mathrm{T} 4$ & $244(79.7 \%)$ & $97(77.6 \%)$ & $0.880(0.532-1.458)$ & 0.620 \\
\hline \multicolumn{5}{|l|}{ Lymph node status } \\
\hline No & $263(85.9 \%)$ & $117(93.6 \%)$ & 1.000 (reference) & \\
\hline $\mathrm{N} 1+\mathrm{N} 2$ & $43(14.1 \%)$ & $8(6.4 \%)$ & $0.418(0.191-0.917)$ & 0.030 \\
\hline \multicolumn{5}{|l|}{ Metastasis } \\
\hline M0 & $294(96.1 \%)$ & $123(98.4 \%)$ & 1.000 (reference) & \\
\hline M1 & $12(3.9 \%)$ & $2(1.6 \%)$ & $0.398(0.088-1.806)$ & 0.233 \\
\hline \multicolumn{5}{|l|}{$\begin{array}{l}\text { Histopathologic } \\
\text { grading }\end{array}$} \\
\hline Low grade & $35(11.4 \%)$ & $18(14.4 \%)$ & 1.000 (reference) & \\
\hline High grade & $271(88.6 \%)$ & $107(85.6 \%)$ & $0.768(0.417-1.414)$ & 0.396 \\
\hline
\end{tabular}


Table 5. Distribution frequency of the clinical status and AURKA rs6024836 genotype frequencies in 431 UCC patients.

\begin{tabular}{|c|c|c|c|c|}
\hline \multirow[b]{2}{*}{ Variable } & \multicolumn{4}{|c|}{ AURKA (rs6024836) } \\
\hline & $\begin{array}{l}\text { AA (\%) } \\
(n=173)\end{array}$ & $\begin{array}{l}\text { AG+GG } \\
(\%)(n=258)\end{array}$ & OR $(95 \% \mathrm{CI})$ & $\begin{array}{l}\mathrm{p} \\
\text { value }\end{array}$ \\
\hline \multicolumn{5}{|l|}{ Stage } \\
\hline $\begin{array}{l}\text { Non muscle invasive } \\
\text { tumor (pTa-pT1) }\end{array}$ & $91(52.6 \%)$ & $144(55.8 \%)$ & 1.000 (reference) & \\
\hline $\begin{array}{l}\text { Muscle invasive } \\
\text { tumor (pT2-pT4) }\end{array}$ & $82(47.4 \%)$ & $114(44.2 \%)$ & $0.879(0.597-1.293)$ & 0.512 \\
\hline \multicolumn{5}{|l|}{ Tumor T status } \\
\hline $\mathrm{Ta}$ & $37(21.4 \%)$ & $53(20.5 \%)$ & 1.000 (reference) & \\
\hline T1-T4 & $136(78.6 \%)$ & $205(79.5 \%)$ & $1.052(0.656-1.688)$ & 0.833 \\
\hline \multicolumn{5}{|l|}{ Lymph node status } \\
\hline No & $147(85 \%)$ & $233(90.3 \%)$ & 1.000 (reference) & \\
\hline $\mathrm{N} 1+\mathrm{N} 2$ & $26(15 \%)$ & $25(9.7 \%)$ & $0.607(0.337-1.091)$ & 0.095 \\
\hline \multicolumn{5}{|l|}{ Metastasis } \\
\hline M0 & $163(94.2 \%)$ & $254(98.4 \%)$ & 1.000 (reference) & \\
\hline M1 & $10(5.8 \%)$ & $4(1.6 \%)$ & $0.257(0.079-0.832)$ & 0.023 \\
\hline \multicolumn{5}{|l|}{$\begin{array}{l}\text { Histopathologic } \\
\text { grading }\end{array}$} \\
\hline Low grade & $19(11 \%)$ & $34(13.2 \%)$ & 1.000 (reference) & \\
\hline High grade & $154(89 \%)$ & $224(86.8 \%)$ & $0.813(0.447-1.478)$ & 0.497 \\
\hline
\end{tabular}

In conclusion, several SNP variants of AURKA are associated with susceptibility to and clinicopathologic status of UCC. Our data provided evidence that carriers of the G/T and $\mathrm{G} / \mathrm{G}$ allele of AURKA rs2064863 were at a lower risk of UCC than wild-type carriers of the $\mathrm{T} / \mathrm{T}$ allele. Thus, the AURKA SNPs may be significant predictors of UCC occurrence and reliable biomarkers of disease progression and metastasis in patients with UCC.

\section{Competing Interests}

The authors have declared that no competing interest exists.

\section{References}

[1] Ajjimaporn A, Botsford T, Garrett SH, Sens MA, Zhou XD, Dunlevy JR, et al. ZIP8 expression in human proximal tubule cells, human urothelial cells transformed by $\mathrm{Cd}+2$ and $\mathrm{As}+3$ and in specimens of normal human urothelium and urothelial cancer. Cancer Cell Int 2012; 12: 16.

[2] Selvaraj V, Govindarajan P, Deepak M, Sivaraj M. "The creeping tumor:" An unusual presentation of upper urinary tract malignancy. Indian J Urol 2014; 30: $454-455$.

[3] Siegel RL, Miller KD, Jemal A. Cancer statistics, 2016. CA Cancer J Clin 2016; 66: 7-30.

[4] Galsky MD, Krege S, Lin CC, Hahn N, Ecke TH, Moshier E, et al. Cisplatin-based combination chemotherapy in septuagenarians with metastatic urothelial cancer. Urol Oncol 2014; 32: 30 e15-21.

[5] Fu J, Bian M, Jiang Q, Zhang C. Roles of Aurora kinases in mitosis and tumorigenesis. Mol Cancer Res 2007; 5: 1-10.

[6] Mobley A, Zhang S, Bondaruk J, Wang Y, Majewski T, Caraway NP, et al. Aurora Kinase A is a Biomarker for Bladder Cancer Detection and Contributes to its Aggressive Behavior. Sci Rep 2017; 7: 40714.

[7] Keen N, Taylor S. Aurora-kinase inhibitors as anticancer agents. Nat Rev Cancer 2004; 4: 927-936.

[8] Chen C, Song G, Xiang J, Zhang H, Zhao S, Zhan Y. AURKA promotes cancer metastasis by regulating epithelial-mesenchymal transition and cancer stem cell properties in hepatocellular carcinoma. Biochem Biophys Res Commun 2017; 486: 514-520.

[9] Puig-Butille JA, Vinyals A, Ferreres JR, Aguilera P, Cabre E, Tell-Marti G, et al. AURKA Overexpression Is Driven by FOXM1 and MAPK/ERK Activation in Melanoma Cells Harboring BRAF or NRAS Mutations: Impact on Melanoma Prognosis and Therapy. J Invest Dermatol 2017; 137: 1297-1310.

[10] Chou CH, Chou YE, Chuang CY, Yang SF, Lin CW. Combined effect of genetic polymorphisms of AURKA and environmental factors on oral cancer development in Taiwan. PLoS One 2017; 12: e0171583.
[11] Wang B, Hsu CJ, Chou CH, Lee HL, Chiang WL, Su CM, et al. Variations in the AURKA Gene: Biomarkers for the Development and Progression of Hepatocellular Carcinoma. Int J Med Sci 2018; 15: 170-175.

[12] Dai ZJ, Kang HF, Wang XJ, Shao YP, Lin S, Zhao Y, et al. Association between genetic polymorphisms in AURKA (rs2273535 and rs1047972) and breast cancer risk: a meta-analysis involving 37,221 subjects. Cancer Cell Int 2014; 14: 91.

[13] Zhou X, Wang P, Zhao H. The Association Between AURKA Gene rs2273535 Polymorphism and Gastric Cancer Risk in a Chinese Population. Front Physiol 2018; 9: 1124.

[14] Bao Z, Lu L, Liu X, Guo B, Zhai Y, Li Y, et al. Association between the functional polymorphism Ile31Phe in the AURKA gene and susceptibility of hepatocellular carcinoma in chronic hepatitis B virus carriers. Oncotarget 2017; 8: 54904-54912.

[15] Su SC, Hsieh MJ, Lin CW, Chuang CY, Liu YF, Yeh CM, et al. Impact of HOTAIR Gene Polymorphism and Environmental Risk on Oral Cancer. J Dent Res 2018; 97: 717-724

[16] Chuang TP, Wang JY, Jao SW, Wu CC, Chen JH, Hsiao KH, et al. Over-expression of AURKA, SKA3 and DSN1 contributes to colorectal adenoma to carcinoma progression. Oncotarget 2016; 7: 45803-45818.

[17] Chou CH, Yang NK, Liu TY, Tai SK, Hsu DS, Chen YW, et al. Chromosome instability modulated by BMI1-AURKA signaling drives progression in head and neck cancer. Cancer Res 2013; 73: 953-966.

[18] Guo XG, Zheng L, Feng WB, Xia Y. The AURKA gene rs2273535 polymorphism contributes to breast carcinoma risk - meta-analysis of eleven studies. Asian Pac J Cancer Prev 2014; 15: 6709-6714.

[19] Lin YC, Hour TC, Tsai YC, Huang SP, Wu WJ, Chen CH, et al. Preliminary evidence of polymorphisms of cell cycle regulatory genes and their roles in urinary tract urothelial cancer susceptibility and prognosis in a Taiwan population. Urol Oncol 2017; 35: 543 e547-543 e516.

[20] Necchi A, Pintarelli G, Raggi D, Giannatempo P, Colombo F. Association of an aurora kinase a (AURKA) gene polymorphism with progression-free survival in patients with advanced urothelial carcinoma treated with the selective aurora kinase a inhibitor alisertib. Invest New Drugs 2017; 35: 524-528.

[21] Lee $\mathrm{CP}$, Chiang SL, Lee $\mathrm{CH}$, Tsai YS, Wang $\mathrm{ZH}$, Hua $\mathrm{CH}$, et al. AURKA Phe31lle polymorphism interacted with use of alcohol, betel quid, and cigarettes at multiplicative risk of oral cancer occurrence. Clin Oral Investig 2015; 19: 1825-1832.

[22] Schultz IJ, Kiemeney LA, Roelofs R, Van Aarssen Y, Babjuk M, Willems JL, et al. The prognostic role of the STK15 T91A polymorphism and of STK15 mRNA expression in patients with urothelial cell carcinoma. Anticancer Res 2007; 27: 1025-1030.

[23] Komoto TT, Bernardes TM, Mesquita TB, Bortolotto LFB, Silva G, Bitencourt TA, et al. Chalcones Repressed the AURKA and MDR Proteins Involved in Metastasis and Multiple Drug Resistance in Breast Cancer Cell Lines. Molecules 2018; 23: E2018.

[24] Goos JA, Coupe VM, Diosdado B, Delis-Van Diemen PM, Karga C, Belien JA, et al. Aurora kinase A (AURKA) expression in colorectal cancer liver metastasis is associated with poor prognosis. Br J Cancer 2013; 109: 2445-2452.

[25] Goos JA, Coupe VM, van de Wiel MA, Diosdado B, Delis-Van Diemen PM, Hiemstra AC, et al. A prognostic classifier for patients with colorectal cancer liver metastasis, based on AURKA, PTGS2 and MMP9. Oncotarget 2016; 7: 2123-2134

[26] Yuan Q, Sun T, Ye F, Kong W, Jin H. MicroRNA-124-3p affects proliferation, migration and apoptosis of bladder cancer cells through targeting AURKA. Cancer Biomark 2017; 19: 93-101. 